\title{
Mycotoxins and Other Secondary Metabolites Produced in vitro by Penicillium paneum Frisvad and Penicillium roqueforti Thom Isolated from Baled Grass Silage in Ireland
}

O'Brien, Martin; Nielsen, Kristian Fog; O'Kiely, Padraig; Forristal, Patrick D.; Fuller, Hubert; Frisvad, Jens Christian

Published in:

Journal of Agricultural and Food Chemistry

Link to article, DOI:

10.1021/jf0621018

Publication date:

2006

Document Version

Publisher's PDF, also known as Version of record

Link back to DTU Orbit

Citation (APA):

O'Brien, M., Nielsen, K. F., O'Kiely, P., Forristal, P. D., Fuller, H., \& Frisvad, J. C. (2006). Mycotoxins and Other Secondary Metabolites Produced in vitro by Penicillium paneum Frisvad and Penicillium roqueforti Thom Isolated from Baled Grass Silage in Ireland. Journal of Agricultural and Food Chemistry, 54(24), 9268-9276. https://doi.org/10.1021/jf0621018

\section{General rights}

Copyright and moral rights for the publications made accessible in the public portal are retained by the authors and/or other copyright owners and it is a condition of accessing publications that users recognise and abide by the legal requirements associated with these rights.

- Users may download and print one copy of any publication from the public portal for the purpose of private study or research.

- You may not further distribute the material or use it for any profit-making activity or commercial gain

- You may freely distribute the URL identifying the publication in the public portal 


\title{
Mycotoxins and Other Secondary Metabolites Produced in Vitro by Penicillium paneum Frisvad and Penicillium roqueforti Thom Isolated from Baled Grass Silage in Ireland
}

\author{
Martin O’Brien, ${ }^{*}, \dagger, \#$ Kristian F. Nielsen, ${ }^{\ddagger}$ Padraig O’Kiely, ${ }^{\dagger}$ \\ Patrick D. Forristal, ${ }^{\S}$ Hubert T. Fuller, ${ }^{\#}$ And Jens C. Frisvad \\ Teagasc, Grange Beef Research Centre, Dunsany, Co. Meath, Ireland; Center for Microbial \\ Biotechnology, BioCentrum-DTU, Technical University of Denmark, Building 221, DK-2800 Kgs. \\ Lyngby, Denmark; Teagasc, Crops Research Centre, Oak Park, Co. Carlow, Ireland; and School of \\ Biology and Environmental Science, College of Life Sciences, University College Dublin, Belfield, \\ Dublin 4, Ireland
}

\begin{abstract}
Secondary metabolites produced by Penicillium paneum and Penicillium roqueforti from baled grass silage were analyzed. A total of 157 isolates were investigated, comprising $78 P$. paneum and $79 P$. roqueforti isolates randomly selected from more than 900 colonies cultured from bales. The findings mostly agreed with the literature, although some metabolites were not consistently produced by either fungus. Roquefortine C, marcfortine A, and andrastin A were consistently produced, whereas PR toxin and patulin were not. Five silage samples were screened for fungal metabolites, with two visually moldy samples containing up to $20 \mathrm{mg} / \mathrm{kg}$ of roquefortine C, mycophenolic acid, and andrastin A along with minor quantities $(0.1-5 \mathrm{mg} / \mathrm{kg})$ of roquefortines $\mathrm{A}, \mathrm{B}$, and $\mathrm{D}$, festuclavine, marcfortine $\mathrm{A}$, and agroclavine. Three visually nonmoldy samples contained low amounts of mycophenolic acid and andrastin A. The ability of both molds to produce a diverse range of secondary metabolites in vitro and in silage should be a concern to livestock producers.
\end{abstract}

KEYWORDS: Penicillium paneum; Penicillium roqueforti; baled grass silage; secondary metabolites; patulin; roquefortine $\mathrm{C}$; mycophenolic acid; PR toxin; andrastin A

\section{INTRODUCTION}

Grass harvested using the baled silage system accounts for approximately $30 \%$ of silage fed annually to livestock in Ireland (1). Recent surveys to establish the incidence of fungal growth on baled grass silage in Ireland have shown that up to $90 \%$ of bales examined had visible fungal growth present $(2-4)$. Fungal growth on silage reduces its nutritional value (5) and may result in the growth of other secondary allergenic, toxigenic, and pathogenic microorganisms $(6,7)$. Fungi of the genera Aspergillus, Penicillium, and Monascus are frequent contaminants of silage $(2,8,9)$, with Penicillium roqueforti (sensu lato) being one of the most common spoilage molds $(2,9-11)$

$P$. roqueforti (sensu lato; subgenus Penicillium) is now considered to consist of three different species, $P$. roqueforti Thom, $P$. paneum Frisvad, and $P$. carneum Frisvad, on the basis of ribosomal and $\beta$-tubulin DNA sequence comparisons, random amplified polymorphic DNA (RAPD) profiles, and secondary metabolite profiles $(11-13)$. Penicillium species isolated from

* Corresponding author [telephone $(+353)$ 4690-61100; fax $(+353) 4690$ 26154; e-mail martin.obrien@teagasc.ie].

$\dagger$ Teagasc, Grange Beef Research Centre.

\# University College Dublin.

$\div$ Technical University of Denmark.

$\S$ Teagasc, Crops Research Centre. baled grass silage in Ireland were almost exclusively represented by $P$. roqueforti and $P$. paneum, and in one study they represented 52 and $4.5 \%$, respectively, of all fungal isolates detected (2). To date, there have been only a few reports of $P$. paneum occurring on silage $(14,15)$ and on feed grain stored under low-oxygen conditions (16), originally misidentified as $P$. roqueforti (11). P. carneum is associated with meat products such as sausages, as well as cheese, bread, and barley (17) and perhaps silage (18). $P$. roqueforti is common on substrates with high levels of organic acids, high concentrations of carbon dioxide, and low levels of oxygen (18); accordingly, silage provides a very favorable substratum for growth of this mold.

The secondary metabolite profiles of $P$. roqueforti, $P$. paneum, and $P$. carneum differ. All three produce roquefortine $\mathrm{C}$ and andrastin $\mathrm{A}$, whereas $P$. roqueforti and $P$. carneum produce mycophenolic acid and both $P$. carneum and $P$. paneum produce patulin. $P$. paneum produces marcfortines and perhaps botryodiplodin, whereas $P$. carneum produces penitrems and $P$. roqueforti PR toxin (Figure 1) (19). The mechanisms by which these mycotoxins could adversely affect the health of livestock are not fully understood. Patulin is known to be antibacterial, cytotoxic, and perhaps even carcinogenic $(19,20)$. PR toxin inhibits protein and RNA synthesis $(21,22)$, is mutagenic in the Salmonella typhimurium assay (23), and is 
<smiles>C[C@H]1C[C@H]2c3cccc4[nH]cc(c34)C[C@H]2N(C)C1</smiles>

Festuclavine

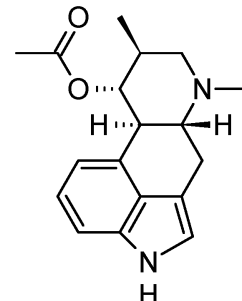

Roquefortine A<smiles>C=CC(C)(C)C12CC3C(=O)N/C(=C\c4cnc[nH]4)C(=O)N3C1Nc1ccccc12</smiles>

Roquefortine C



Marcfortine A<smiles>COc1c(C)c2c(c(O)c1C/C=C(\C)CCC(=O)O)C(=O)OC2</smiles>

Patulin<smiles>O=C1C=C2C(=CCOC2O)O1</smiles><smiles>O=C(O)c1cccc(O)c1</smiles>

3-Hydroxybenzoic acid

PR toxin<smiles>CCO[O+]([O-])O[Na]</smiles><smiles>Cc1cc(O)cc(=O)o1</smiles>

\section{Triacetic acid lactone}

Figure 1. Structures of selected described metabolites from $P$. roqueforti and $P$. paneum in this and other studies.

carcinogenic in rats (24). Mycophenolic acid is antibacterial and immunosuppressive in higher animals (25). In a feeding experiment with sheep, no roquefortine toxicity was revealed (26); however, others have shown it to be antibacterial (27), and in a more recent study, it (and mycophenolic acid) has been shown to be highly toxic when inhaled by mice (28). The toxicological properties of andrastin A, previously "metabolite A" (12), are unknown, but it is present in all blue cheeses (29) and has been considered for use as an anticancer agent (30).

Acute toxic syndromes and even fatal poisoning of unknown etiology have been observed in livestock that have consumed molded silage $(31-33)$. With improved methods for the detection of mycotoxins in feed, it is becoming apparent that mycotoxins are regularly formed in silage $(10,34)$. Roquefortine $\mathrm{C}$ and mycophenolic acid are the two most frequently detected mycotoxins produced by the $P$. roqueforti group in silage $(10$, 35), whereas PR toxin and patulin have been detected only occasionally owing to their unstable nature in this substratum $(9,36)$.

Previous studies have screened Penicillia from a wide variety of substrata for secondary metabolite production, but no study to date has explored the consistency of secondary metabolite production by a large number of Penicillium isolates from grass silage. There is also a gap in our knowledge as to the types of secondary fungal metabolites commonly present in moldcontaminated silage. This study aimed to characterize the secondary metabolite profiles of $P$. roqueforti and $P$. paneum isolated from baled grass silage in Ireland, to induce $P$. paneum isolates to produce patulin by supplementing the growth medium with trace metals, for example, manganese, and to assess the ability of these $P$. paneum isolates to produce patulin after storage for 30 weeks. Another objective was to screen visually moldy and visually nonmoldy grass silage samples for secondary fungal metabolites.

\section{MATERIALS AND METHODS}

Sample Collection and Isolate Selection. The incidence of fungal growth on baled grass silage ( $n=464$ bales) on Irish farms $(n=235$ farms) was recorded in three separate studies undertaken in March 2003 (2), from November 2003 to March 2004 (3), and in February 2004 (4). A total of 2277 visible fungal colonies were enumerated on these bales, and 1190 fungal colonies were sampled and later identified following an established protocol (2). Of this total, 830 were identified as $P$. roqueforti and 78 as $P$. paneum by their macro- and micromorphology features, using appropriate identification keys $(18,37)$. Approximately $10 \%$ of the $P$. roqueforti isolates were chosen with the random function in Microsoft Office Excel, and these selected isolates $(n=79)$ were screened for their secondary metabolites. All $78 P$. paneum isolates were screened for secondary metabolite production. The isolates selected, of both species, were sourced from 102 bales on 77 farms. Isolates were maintained throughout the study on malt extract agar (MEA) plates (Oxoid, Basingstoke, U.K.) at $2-4{ }^{\circ} \mathrm{C}$ in darkness and were subcultured no more than six times prior to secondary metabolite analyses.

In a separate study, silage samples from three bales sourced from different farms (one bale per farm) were collected. A visually moldy and a visually nonmoldy sample were collected from two of the bales (i.e., two samples per bale), and a fifth sample was taken from a third bale free of all visible mold growth on its surface. A representative silage grab sample (100 g) was collected in each case. The visible mold on the surface of two of these bales was recognized as Penicillium spp., and a small sample of mold was collected from each bale for species identification. Silage samples were stored at ca. $4{ }^{\circ} \mathrm{C}$ while in transit and then at $-18{ }^{\circ} \mathrm{C}$ until required for secondary metabolite analysis. Five grab samples of silage were taken from nonmoldy parts of each of these bales and assayed for dry matter (DM) concentration by drying $\left(85^{\circ} \mathrm{C}\right.$ for $\left.16 \mathrm{~h}\right)$ in a forced-air oven.

Growth Media and Conditions. Screening Penicillium Isolates for Secondary Metabolites. Penicillium isolates were three-point-inoculated onto yeast extract sucrose (YES) agar (18) and Czapek yeast autolysate agar (CYA) (17) and incubated for 7 days at $25{ }^{\circ} \mathrm{C}$ in darkness. The yeast extract in both media was purchased from Difco (Becton Dickinson and Co., Franklin Lakes, NJ). To induce patulin production 
in $P$. paneum, isolates were three-point-inoculated onto potato dextrose agar (PDA) (Oxoid) and incubated for 7 days at $25^{\circ} \mathrm{C}$ in darkness.

Inducing P. paneum Isolates To Produce Patulin. PDA medium supplied by Difco (Becton Dickinson and Co.) was supplemented with $0.003 \% \mathrm{MnCl}_{2} \cdot 4 \mathrm{H}_{2} \mathrm{O}(38), 0.001 \% \mathrm{ZnSO}_{4} \cdot 7 \mathrm{H}_{2} \mathrm{O}$, and $0.0005 \% \mathrm{CuSO}_{4} \cdot$ $5 \mathrm{H}_{2} \mathrm{O}$. Forty-two $P$. paneum isolates in which patulin was not detected when grown on CYA, YES, and Oxoid PDA were inoculated onto the medium as outlined above, incubated for 7 days at $25{ }^{\circ} \mathrm{C}$ in darkness, and rescreened for their ability to produce patulin.

Assessing the Ability of P. paneum Isolates To Produce Patulin after a Prolonged Storage Period. Eleven isolates identified as producers of patulin were rescreened for their ability to produce patulin after 30 weeks of storage on MEA at $2-4{ }^{\circ} \mathrm{C}$. These isolates were inoculated onto PDA (Oxoid) as outlined above and incubated for 7 days at 25 ${ }^{\circ} \mathrm{C}$ in darkness before being analyzed for patulin production.

Secondary Metabolite Extraction from Cultures. Extraction of secondary metabolites was based on a standard method for cultures grown on solid medium (39). Five agar plugs were removed from a Penicillium colony on CYA and likewise from a YES plate and additionally from PDA for P. paneum isolates. Plugs were cut with a stainless steel corer (diameter $=6 \mathrm{~mm}$ ) under aseptic conditions and collectively transferred to a $4-\mathrm{mL}$ glass vial (10-15 agar plugs per vial for each isolate). To each vial was added $1.8 \mathrm{~mL}$ of solvent (ethyl acetate/dichloromethane/methanol, 3:2:1, v/v/v, $+1 \%$ formic acid) (39), and the mixture was left overnight. All solvents were of HPLC grade, and formic acid was of analytical grade. The liquid fraction was decanted into clean 4-mL glass vials and evaporated in vacuo in a vacuum centrifuge at $1 \mathrm{mbar}$ for $\sim 35 \mathrm{~min}$ or by passing pure nitrogen over the solvent using a drying block set to $35^{\circ} \mathrm{C}$. The samples were then redissolved in $500 \mu \mathrm{L}$ of methanol (HPLC grade) and kept for $1-2 \mathrm{~h}$ with intermittent shaking, before filtering through a $0.45-\mu \mathrm{m}$ Teflon syringe filter (SRI, Eatontown, NJ) into a 2-mL vial before HPLC analysis.

Secondary Metabolite Extraction from Silage Samples. One gram samples were transferred to $16-\mathrm{mL}$ extraction vials and extracted using $10 \mathrm{~mL}$ of ethyl acetate for $\sim 3 \mathrm{~h}$ in a shaker at $\sim 200 \mathrm{rpm}$ and subsequently filtered through a Whatman (Brentford, U.K.) PS1 phase separation filter. The ethyl acetate was then evaporated in vacuo, reconstituted in $3 \times 1.0 \mathrm{~mL}$ of water containing $0.5 \%$ formic acid, and loaded onto a $60 \mathrm{mg}$ Strata-X module (Phenomenex, Torrance, CA). The solid-phase extraction (SPE) cartridge had previously been conditioned with $2 \mathrm{~mL}$ of methanol and $2 \mathrm{~mL}$ of water containing $0.5 \%$ formic acid. After sample loading, the cartridge was washed with 2 $\mathrm{mL}$ of water containing $0.5 \%$ formic acid and eluted with $80 \%$ acetonitrile/water containing $0.2 \%$ formic acid, and the eluate was evaporated in vacuo. The sample was redissolved in $2 \times 100 \mu \mathrm{L}$ of methanol and filtered through a $0.45-\mu \mathrm{m}$ PFTE syringe filter (Chromacol, Herts, U.K.) into a 2-mL vial. Fortified samples were prepared (in duplicate) by the addition of $100 \mu \mathrm{L}$ of ethyl acetate mixture of penicillic acid, mycophenolic acid, roquefortine $\mathrm{C}$, and patulin in levels of 60,15 , and $2 \mu \mathrm{g} / \mathrm{g}$.

HPLC Analysis. Culture extracts were analyzed on an Agilent (Torrance, CA) 1100 liquid chromatographic system equipped with a photodiode array detector (DAD), a fluorescence detector, and a 100 $\times 2 \mathrm{~mm}$ i.d., $3 \mu \mathrm{m}$, Luna $\mathrm{C}_{18}$ II column (Phenomenex) fitted with a Phenomenex SecurityGuard $\mathrm{C}_{18}$ precolumn. Two different water/ acetonitrile systems were used at a flow rate of $0.4 \mathrm{~mL} / \mathrm{min}$. The first (standard system) started at $15 \% \mathrm{CH}_{3} \mathrm{CN}$, which was increased to $100 \%$ over $20 \mathrm{~min}$ and then held at $100 \%$ for $5 \mathrm{~min}$. The second system started at 5\% acetonitrile for $3 \mathrm{~min}$ before increasing to $100 \%$ over 17 min and then holding at $100 \%$ for 5 min. Sample volumes of $1-5 \mu \mathrm{L}$ were injected onto the column.

HPLC-MS Analysis. Silage samples as well as representative culture extracts were also analyzed by liquid chromatography-electrospray high-resolution mass spectrometry, using a Micromass LCT orthogonal time of flight mass spectrometer (Micromass, Manchester, U.K.) equipped with a Z-spray electrospray source and a LockSpray probe. The LC system was the same as described above except that the column was $50 \mathrm{~mm}$ long and a fluorescence detector was not used. Samples were analyzed in both negative and positive electrospray modes with gradient systems started at 5 and/or $15 \%$ acetonitrile $(11,40)$.
Analysis of HPLC and HPLC-MS Data. Peaks, excluding those found in noninfected silage samples or from blank agar plates, were matched against an internal reference standard database ( $630 \mathrm{com}-$ pounds) (41), and occasionally some of the following metabolites were included in the same sequence as the samples: cyclopiazonic acid; cyclopaldic acid; gentisyl alcohol; mycophenolic acid; orsellinic acid; patulin; penicillic acid; penitrem A; PR toxin; roquefortines A-D; agroclavine I; festuclavine; secoclavine; citreoisocoumarin; marcfortines A and B; 6-methylsalicylic acid; salicylic acid; 2,5-dihydroxybenzoic acid; 2,4-dihydroxybenzoic acid; andrastins A and E; linolenic acid; 3-hydroxybenzoic acid; bis(dethio)bis(methylthio)gliotoxin; gliotoxin; and 4-methylsalicylic acid.

\section{RESULTS AND DISCUSSION}

$P$. roqueforti and $P$. paneum Secondary Metabolites in Culture. The range of secondary metabolites detected in both $P$. roqueforti and $P$. paneum in this study (Tables $\mathbf{1}$ and $\mathbf{2}$, respectively) was broadly in agreement with the findings of previous studies $(11,12,19)$, but not all metabolites were consistently produced (Table 3). Figures $\mathbf{2}$ and $\mathbf{3}$ show HPLCUV chromatograms of typical $P$. roqueforti and $P$. paneum extracts, respectively, with the predominant peaks identified. Approximately $90 \%$ of $P$. roqueforti isolates were consistent producers of roquefortine $\mathrm{C}$ and andrastin $\mathrm{A}$, but varied greatly in their ability to produce roquefortine A, citreoisocoumarin, andrastin $\mathrm{C}$, PR toxin, eremofortin $\mathrm{C}$, and an unidentified metabolite. This unidentified metabolite is probably an analogue of scytalone or hydroxymellein and had a molecular composition of $\mathrm{C}_{10} \mathrm{H}_{10} \mathrm{O}_{4}$ (from $\mathrm{ESI}^{-} \mathrm{LC}-\mathrm{MS}$, mass deviation $<5 \mathrm{ppm}$ ). UV absorptions were $216 \mathrm{~nm}(100 \%), 260 \mathrm{~nm}(62 \%)$, and $334 \mathrm{~nm}$ $(21 \%)$. Patulin, marcfortine, gentisic acid, and botryodiploidin production by $P$. roquefort $i$ were not detected. The majority of $P$. paneum isolates were consistent producers of andrastin A, citreoisocumarin, marfortines, and roquefortine $\mathrm{C}$ but were not consistent in their ability to produce roquefortine A, andrastin $\mathrm{C}$, gentisic acid, and patulin (Table 3). Lack of consistency in metabolite production was also observed in isolates collected from the same silage bale (e.g., isolates WH121E-WH121M in Table 2). Nonproduction of patulin by $P$. paneum has been reported previously (11); however, in this study, the $P$. paneum isolates that did not produce patulin produced 6-methylsalicylic acid, which is a patulin precursor. It is not known if these isolates are unable to synthesize patulin or in certain circumstances shunt precursors toward the synthesis of other metabolites. Roquefortine $\mathrm{C}$ and andrastin $\mathrm{A}$ were the two most consistently produced metabolites by both species, and in the case of roquefortine $\mathrm{C}, P$. roqueforti typically produced 5-20fold more than $P$. paneum. The ratio of mycophenolic acid and PR toxin production was found to vary greatly among $P$. roqueforti isolates; the mean ratio was ca. 50:1 (range from $<0.01: 1$ to $424: 1$ ), with more mycophenolic acid produced than PR toxin in most cases (Table 1). $P$. paneum did not produce detectable amounts of mycophenolic acid, PR toxin, botryodiploidin, metabolite $\mathrm{T}$, and eremofortine. A report on botryodiploidin production by $P$. paneum (42), identified originally as $P$. roqueforti (11), could not be confirmed in this study, but perhaps with different cultural conditions it may have been possible to induce its production.

Factors Affecting Patulin Production. Trace Metal Enriched Difco PDA. Production of secondary metabolites by Penicillium species is generally favored on CYA and YES media (43), but there are exceptions. P. paneum, for example, will produce patulin only when grown on PDA and occasionally on YES (11). There is also anecdotal evidence to suggest that Difco PDA is better for patulin production than Oxoid PDA. When 
Table 1. Secondary Metabolites Produced in Culture by $P$. roqueforti $(n=79$ Isolates) Isolated from Baled Grass Silage in Ireland

\begin{tabular}{|c|c|c|c|c|c|c|c|c|c|c|c|c|c|c|c|c|c|c|c|c|c|c|c|}
\hline isolate ${ }^{a, c}$ & $\begin{array}{l}\text { IBT } \\
\text { no. }^{d}\end{array}$ & $\mathrm{RA}^{f}$ & $\mathrm{RC}$ & $\mathrm{CIC}$ & $\mathrm{AA}$ & $A X$ & SC & $\mathrm{EC}$ & MPA & PR & $\begin{array}{c}\text { MPA/PR } \\
\text { ratio }^{e}\end{array}$ & isolate ${ }^{a, c}$ & $\begin{array}{l}\text { IBT } \\
\text { no. }^{d}\end{array}$ & $\mathrm{RA}^{f}$ & $\mathrm{RC}$ & $\mathrm{CIC}$ & AA & $A X$ & SC & EC & MPA & PR & $\begin{array}{c}\text { MPA/PR } \\
\text { ratioe }^{e}\end{array}$ \\
\hline CN100E & 25410 & + & + & & + & & & + & + & + & 2.70 & MH02D & 25374 & + & + & + & + & & + & + & + & + & 2.23 \\
\hline CN102A & 25416 & + & + & & + & & + & + & + & & na & $\mathrm{MH} 02 \mathrm{~F}^{b}$ & 25371 & + & + & & + & + & + & + & + & + & 0.02 \\
\hline CN104C & 25386 & + & + & + & + & & + & + & + & + & 45.18 & $\mathrm{MH} 03 \mathrm{C}^{b}$ & 25334 & + & + & + & $\operatorname{tr}$ & + & + & + & + & + & 1.25 \\
\hline $\mathrm{CN}_{105 \mathrm{C}_{1}}$ & 25370 & & + & & + & & + & + & + & + & 6.80 & MH03G & 25367 & + & + & & + & & + & & & & na \\
\hline $\mathrm{CN} 105 \mathrm{C}_{2}$ & 25408 & + & + & + & + & & & + & + & + & 31.40 & $\mathrm{MH} 04 \mathrm{~F}^{b}$ & 25337 & + & + & + & + & + & & + & + & & na \\
\hline $\mathrm{G}_{203 B_{1} b}$ & & & + & + & + & + & & & + & + & 0.97 & МH07B & 25470 & & + & & + & & & + & + & + & 99.21 \\
\hline $\mathrm{G}_{2} 03 \mathrm{~B}_{2}{ }^{b}$ & & & + & + & + & & & & + & + & 0.72 & MH08F & 25378 & & + & + & + & + & + & + & + & + & 85.63 \\
\hline $\mathrm{KE} 10 \mathrm{D}_{2}$ & 25376 & + & + & + & + & + & + & + & + & + & 6.14 & MH09E & & & + & & + & + & & & + & + & 3.40 \\
\hline KE10G & 25373 & + & + & + & + & + & + & + & & & na & $\mathrm{MH} 10 \mathrm{~A}$ & 25335 & + & + & & + & & + & + & + & + & 26.53 \\
\hline KE11B & 25377 & + & + & & & & & + & + & + & 24.53 & MH12D & 25395 & & + & + & + & + & & + & + & + & 7.18 \\
\hline $\mathrm{KE} 11 \mathrm{G}^{b}$ & 25372 & + & + & + & + & & + & & + & & na & $\mathrm{MH} 14 \mathrm{C}^{b}$ & 25336 & + & + & & + & + & & + & + & + & 0.45 \\
\hline KE17E & 25369 & + & + & + & + & + & + & + & & & na & OY100G & 25418 & + & + & + & + & + & + & + & & & na \\
\hline KE18C & 25375 & & + & & + & & + & + & + & + & 28.51 & OY101B & 25417 & + & + & & + & & + & + & + & + & 7.07 \\
\hline KE18F & 25384 & + & + & + & + & + & + & + & & + & na & OY107C & 25404 & + & + & & + & & + & + & + & + & 38.69 \\
\hline $\mathrm{KE} 18 \mathrm{G}^{b}$ & 25389 & + & + & & + & & + & + & + & + & $<0.01$ & OY108A & 25385 & + & + & & + & + & + & + & + & + & 45.55 \\
\hline KE19E & 25400 & + & + & + & + & + & + & & + & + & 16.33 & OY109C & 25382 & + & + & & + & & + & + & + & + & 1.33 \\
\hline KE19| ${ }^{b}$ & & & + & + & + & & & & + & + & 117.83 & OY111H & 25381 & + & + & & + & & + & + & & & na \\
\hline KE25D & 25390 & + & & + & + & & + & & + & & na & OY111K & 25473 & + & + & & + & & & + & & & na \\
\hline KE28G ${ }^{b}$ & 25338 & + & + & & + & + & & & + & & na & OY113Fb & & & & + & + & + & & + & + & + & 1.25 \\
\hline KE28I & 25387 & & + & & & & & + & + & + & 137.73 & $\mathrm{OY}_{128 \mathrm{~T}_{1}}^{b}$ & & & + & + & + & & & & + & + & 0.01 \\
\hline KE29E & 25368 & + & + & + & + & & + & + & + & + & 107.75 & $\mathrm{RN} 209 \mathrm{~B}^{b}$ & & & + & & + & & & + & + & + & 21.53 \\
\hline KE29H & 25471 & + & + & + & + & & + & + & + & + & 178.80 & TN101C & 25419 & & + & & + & + & & + & & & na \\
\hline KE29I & 25396 & + & + & + & + & & + & + & + & + & 6.29 & TN102A & 25472 & & + & & + & & + & & + & + & 28.40 \\
\hline KK09A & 25399 & + & + & & + & & + & + & + & + & 6.31 & TN103C & 25429 & + & + & & + & & & + & + & + & 106.90 \\
\hline $\mathrm{KK} 09 \mathrm{~B}^{b}$ & 25388 & + & + & & + & + & + & + & + & + & 47.28 & TN106H & 25398 & + & + & & + & & + & + & & & na \\
\hline LD100A & 25421 & + & + & & + & & + & + & + & + & 33.55 & TN106I & 25426 & + & + & & + & & & + & + & + & 116.30 \\
\hline LD100E & 25422 & & + & & + & + & + & + & + & + & 9.93 & TN107A & 25403 & + & + & & + & + & + & + & + & + & 17.95 \\
\hline LD101B & 25424 & & + & & + & + & & + & + & + & 37.50 & TN107I & 25405 & & + & & + & & + & + & + & + & 53.83 \\
\hline LD101F & 25420 & & + & & + & & & + & + & + & 70.71 & TS12B & 25379 & + & + & & + & + & + & & + & & na \\
\hline LD102B & 25412 & + & + & & + & & & + & + & + & 97.55 & TS14C & 25383 & + & & & + & & & + & + & + & 61.95 \\
\hline LD103D & 25411 & + & + & & + & & & + & + & + & 50.50 & WH100A & 25414 & & + & & + & & & & + & + & 6.31 \\
\hline LD104G & 25409 & + & + & + & + & & & & + & + & 200.00 & WH100F & 25413 & + & + & + & + & + & & & + & + & 424.70 \\
\hline LD104I 2 & 25401 & + & + & & + & + & + & + & + & + & 22.07 & WH101E & & + & + & & + & & & & + & + & 1.98 \\
\hline LD105B & 25406 & & + & + & + & & + & + & + & + & 209.33 & WH102E & 25407 & + & + & & + & + & + & + & + & + & 98.73 \\
\hline LD105D & 25402 & + & + & & & & & + & + & + & 44.59 & $\mathrm{WH} 103 \mathrm{~B}_{2}$ & 25397 & + & + & & & & & + & + & + & 23.45 \\
\hline LS01G & 25391 & + & + & + & & + & + & + & + & & na & $\mathrm{WH} 103 \mathrm{~B}_{1}$ & 25427 & + & + & & + & + & & + & & & na \\
\hline LS04A & 25392 & + & + & + & + & + & + & + & + & + & 10.69 & WH103E & 25333 & + & + & + & & + & + & + & & & na \\
\hline $\mathrm{LS} 05 \mathrm{~A}^{b}$ & 25393 & & + & + & + & & + & + & & & na & $W X 210 A^{b}$ & & & + & & + & & + & + & + & + & 0.01 \\
\hline LSO6H & 25380 & + & + & + & & & & + & + & + & 15.53 & & & & & & & & & & & & \\
\hline LS08A & 25394 & + & + & + & + & & + & + & + & + & 1.88 & & & & & & & & & & & & \\
\hline $\mathrm{LS} \mathrm{BC}^{b}$ & & & + & + & + & & & + & + & + & 0.47 & & & & & & & & & & & & \\
\hline
\end{tabular}

${ }^{a}$ Isolates were grown on YES and CYA media for 7 days at $25^{\circ} \mathrm{C}$, and secondary metabolites were extracted from both media and analyzed using LC-UV. ${ }^{b}$ The presence of metabolites was confirmed using LC-MS; +, denotes the presence of a metabolite; tr, trace. ${ }^{c}$ Isolates denoted by the same two-letter code followed by an identical two- or three-digit number were collected from different points on the same bale of silage. ${ }^{d}$ IBT, culture collection at the Centre for Microbial Biotechnology, Lyngby, Denmark. ${ }^{e}$ The peak area of mycophenolic acid was compared to PR toxin and the ratio calculated; na, not applicable. ${ }^{f}$ Abbreviations: RA, roquefortine A (isofumigaclavine A); RC, roquefortine $\mathrm{C}$; $\mathrm{CIC}$, citreoisocoumarin; $\mathrm{AA}$, andrastin $\mathrm{A} ; \mathrm{AC}$, andrastin $\mathrm{C}$; $\mathrm{SC}$, scytalone or hydroxymellein derivative (see text); $\mathrm{EC}$, eremofortin C; MPA, mycophenolic acid and analogues; PR, PR toxin.

$50 \%(39 / 78)$ of the $P$. paneum isolates screened in this study failed to produce detectable amounts of patulin on Oxoid PDA, they were re-inoculated onto Difco PDA supplemented with trace metals (i.e., manganese, zinc, and copper). For metabolite analyses, zinc and copper have routinely been included in YES and CYA media, as in this study, and the addition of manganese has been shown to be important for patulin production in a number of different Penicillium spp. (38). However, only 4/39 isolates were induced to produce patulin on the modified medium. The addition of manganese to PDA is known to enhance patulin production by increasing the conversion of 6-methylsalicylic acid to patulin in a number of Penicillium spp. $(38,44)$. In this study, the addition of manganese resulted in a 5-20-fold increase in the peak area of 3-hydroxybenzoic acid (a patulin precursor) and citreoisocoumarin, indicating that the addition of manganese may redirect synthesis toward citreoisocoumarin from 3-hydroxybenzoic acid rather than patulin.

Storage. To investigate if storage can have an effect on patulin production, $11 P$. paneum isolates that were known to be patulin producers were rescreened for their production after a further 30 weeks of storage at $2-4{ }^{\circ} \mathrm{C}$. Following storage, no detectable levels of patulin could be found in 4 isolates; levels were reduced on average by $77 \%$ in 3 isolates and were raised, on average, by $68 \%$ in the remaining 4 of the 11 isolates tested.

In relation to storage, a further anomaly was the inconsistency in patulin production in two different batches of $P$. paneum isolates. One batch consisting of 19 isolates was collected in March 2003, and 12 of the 19 (63\%) isolates produced patulin. In contrast, in a second batch of isolates collected from November 2003 to March 2004, only 27 of 59 (45\%) isolates were patulin producers. This is of interest because the first batch was in storage for approximately 72 weeks prior to analysis and was subcultured more frequently, whereas the second batch was in storage for approximately 33 weeks prior to analysis and subcultured less frequently. Others (45) have reported that patulin production decreases with time for Penicillium expansum when preserved by subculturing and maintenance at $4{ }^{\circ} \mathrm{C}$. The same authors found that patulin production and detection were 
Table 2. Secondary Metabolites Produced in Culture by P. paneum ( $n=78$ Isolates) Isolated from Baled Grass Silage in Ireland

\begin{tabular}{|c|c|c|c|c|c|c|c|c|c|c|c|c|c|c|c|c|c|c|c|}
\hline isolate ${ }^{a, b}$ & $\begin{array}{l}\text { IBT } \\
\text { no. }{ }^{c}\end{array}$ & $\mathrm{RA}^{e}$ & $\mathrm{RC}$ & $\mathrm{ClC}$ & $\mathrm{AA}$ & $A C$ & MA & PA & $\mathrm{GA}$ & isolate ${ }^{a, b}$ & $\begin{array}{l}\text { IBT } \\
\text { no. }{ }^{c}\end{array}$ & $\mathrm{RA}^{e}$ & $\mathrm{RC}$ & $\mathrm{CIC}$ & $\mathrm{AA}$ & $A C$ & MA & PA & GA \\
\hline C203A & & & + & + & + & & + & + & + & OY112H & & & tr & + & + & + & + & + & \\
\hline CN100J & & & + & + & + & & + & & & OY113A & & & tr & + & + & + & + & $+^{d}$ & \\
\hline CN100K & 25415 & & $\operatorname{tr}$ & + & + & + & + & & & OY116D & & & + & + & + & & + & & \\
\hline CN103C & & & tr & + & + & & + & $+^{d}$ & & OY118B & & & $\operatorname{tr}$ & + & + & & + & + & \\
\hline CN204A & & + & + & + & + & & + & + & & OY118K & & & tr & + & + & & tr & + & \\
\hline DL205A & & & + & + & + & & + & & & OY122C & & & tr & + & + & & + & + & \\
\hline DL227A & & + & + & + & + & & + & + & & OY123A & & & + & + & + & & + & & \\
\hline DL251J & & & + & + & + & & + & & & OY127E & & + & + & + & + & & + & $+^{d}$ & \\
\hline DL253A & & & + & + & + & & + & + & + & OY127H & & + & + & + & + & + & + & & \\
\hline G216B & & + & $\operatorname{tr}$ & + & + & & + & & & OY127I & & + & + & + & + & & + & + & \\
\hline G218A & & + & + & + & + & & + & + & & OY128H & & + & + & + & + & & + & & \\
\hline G223A & & + & + & + & + & & + & + & & OY1280 & & + & + & + & + & & + & & \\
\hline KE26B & & + & + & + & + & + & + & + & & OY129B & & & + & + & + & & + & + & \\
\hline KE26C & & + & + & + & + & + & + & & & RN203A & & + & + & + & + & & + & + & \\
\hline KE27D & & & + & + & + & + & + & + & & SO202A & & + & + & + & + & & + & & \\
\hline KE27E & & + & + & + & + & & + & + & & TN103A & & + & & + & + & & + & & \\
\hline KE28B & & + & + & + & + & + & + & + & & TN104C & & & $\operatorname{tr}$ & + & + & & + & & \\
\hline KE28C & & + & + & + & + & & + & + & & TS13G & & + & + & + & + & + & + & & \\
\hline KE28D & & + & tr & + & + & & + & + & & TS20G & & + & + & + & + & & + & & \\
\hline KE29F & & & tr & + & + & & + & + & & WD203A & & & tr & + & + & & + & + & \\
\hline KE29G & & & + & + & + & & + & & & WD208A & & + & $\operatorname{tr}$ & + & + & & + & & \\
\hline KK04A & 25331 & & + & + & + & + & + & + & + & WD214A & & & + & + & + & & & + & \\
\hline KK04B & 25332 & + & + & + & + & & + & + & + & WD217A & & & + & + & + & & + & & \\
\hline KK06B & & & + & + & + & & + & & & WH101C & 25423 & & + & + & + & & + & & \\
\hline KK08B & & + & + & + & + & & + & & & WH105D & & + & + & + & + & & + & + & \\
\hline KK214B & & & + & + & + & & + & & & WH109D & & & $\operatorname{tr}$ & + & + & & + & & \\
\hline KY222B & & + & + & + & + & & + & & & WH109F & & + & + & + & + & & + & + & + \\
\hline LD104I1 & 25330 & + & + & + & + & + & + & + & & WH113D & & + & tr & + & + & & + & + & \\
\hline LD106C & & + & + & + & + & + & + & & + & WH115B & & + & & + & + & & + & + & \\
\hline LK207A & & + & + & + & + & & + & & & WH116H & & + & + & + & + & & + & $+^{d}$ & \\
\hline LK210B & & & + & + & + & + & & & & WH120S & & & + & + & + & + & + & & \\
\hline LK225B & & & + & + & + & + & + & + & & WH121E & & & + & + & + & & + & & \\
\hline LS06C & & + & tr & + & + & & + & + & & WH121G & & + & tr & + & + & & + & + & \\
\hline LS06E2 & & + & + & + & + & & + & + & & WH121H & & & + & + & + & & + & & \\
\hline LS08E2 & & + & + & + & + & & + & + & & WH121I & & + & + & + & + & & + & & \\
\hline $\mathrm{MH} 08 \mathrm{G}$ & & + & + & + & + & & + & & & WH121J & & & + & + & + & & + & & \\
\hline MN204B & & + & + & + & + & & + & & & WH121K & & & tr & + & + & & + & & \\
\hline MO204A & & + & + & + & + & + & + & + & & WH121L & & & + & + & + & + & + & & \\
\hline OY112C & & + & + & + & + & & + & & & WH121M & & & + & + & + & & + & & \\
\hline
\end{tabular}

${ }^{a}$ Isolates were grown on YES, CYA, and PDA media for 7 days at $25^{\circ} \mathrm{C}$. Secondary metabolites were extracted from the media and analyzed using LC-UV and LC-MS. ${ }^{b}$ Isolates denoted by the same two-letter code followed by an identical two- or three-digit number were collected from different points on the same bale of silage. ${ }^{c}$ IBT, culture collection at Centre for Microbial Biotechnology, Lyngby, Denmark. ${ }^{d}$ Patulin production detected only when grown separately on Difco PDA supplemented with manganese and other trace metals. ${ }^{e}$ Abbreviations: RA, roquefortine $\mathrm{A}$ (isofumigaclavine $\mathrm{A}$ ); $\mathrm{RC}$, roquefortine $\mathrm{C}$; $\mathrm{CIC}$, citreoisocoumarin; $\mathrm{AA}$, andrastin $\mathrm{A} ; \mathrm{AC}$, andrastin C; MA, marcfortine A; PA, patulin; GA, gentisic acid; +, denotes the presence of a metabolite; tr, trace.

Table 3. Consistency of Secondary Metabolite Production in Culture by $P$. roqueforti and $P$. paneum Isolates from Baled Grass Silage in Ireland

\begin{tabular}{lcc}
\hline & \multicolumn{2}{c}{ no. of isolates ${ }^{a}$ (\% of total isolates) } \\
\cline { 2 - 3 } secondary metabolite & $P$. roqueforti $(n=79)$ & $P$. paneum $(n=78)$ \\
\hline mycophenolic acid and & $67(84.8)$ & $\mathrm{ND}$ \\
$\quad$ & & \\
analogues & $55(69.6)$ & $42(53.8)$ \\
roquefortine A & $76(96.2)$ & $76(97.4)$ \\
roquefortine C & $\mathrm{ND}$ & $76(97.4)$ \\
marcfortines & $33(41.7)$ & $78(100)$ \\
citreoisocoumarin & $72(91.1)$ & $78(100)$ \\
andrastin A & $30(38.0)$ & $17(21.8)$ \\
andrastin C & $45(57.0)$ & $\mathrm{ND}$ \\
metabolites T & $61(77.2)$ & $\mathrm{ND}$ \\
PR toxin & $63(79.7)$ & $\mathrm{ND}$ \\
eremofortin C & $\mathrm{ND}$ & $39(50)$ \\
patulin & $\mathrm{ND}$ & $6(7.7)$ \\
gentisic acid & & \\
& &
\end{tabular}

\section{${ }^{a} \mathrm{ND}$, not detected.}

more consistent in $P$. expansum preserved using silica gel or the freeze-drying methods, compared to subculturing and maintenance at $4{ }^{\circ} \mathrm{C}$.
$P$. roqueforti and $P$. paneum Secondary Metabolites in Silage. The chromatograms in Figure $\mathbf{4}$ clearly confirm the presence of andrastin A, mycophenolic acid, roquefortines A and $\mathrm{C}$, marcfortine $\mathrm{A}$, and festuclavine in mold-contaminated silage. The recoveries ( \pm standard deviation, three levels analyzed in duplicate) of metabolites were determined to be 80 $\pm 15 \%$ for roquefortine C, $70 \pm 10 \%$ for mycophenolic acid, $40 \pm 20 \%$ for patulin, and $60 \pm 20 \%$ for penicillic acid. Patulin was detected by UV at $276 \mathrm{~nm}$ and $\mathrm{ESI}^{-}$as the $[\mathrm{M}-\mathrm{H}]^{-}$ion and penicillic acid as the $[\mathrm{M}-\mathrm{H}]^{-}$ion with an approximate limit of detection of $0.1-0.5 \mathrm{mg} / \mathrm{g}$ of silage. As sufficient quantities of the marcfortines and roquefortines $\mathrm{A}, \mathrm{B}, \mathrm{D}$, and $\mathrm{OH}-\mathrm{C}$ (detected by $\mathrm{ESI}^{+}$) were not available for a fortification experiment, the quantities of these were estimated from calibration curves using pure substances and also assuming the same recovery as for roquefortine $\mathrm{C}$ and a detection limit of 40-200 $\mu \mathrm{g} / \mathrm{kg}$ of silage estimated from the lowest amount of the fortified sample (2 mg/kg). Mycophenolic acid and andrastin A were detected in both polarities with a negative LC-ESI-MS being most sensitive, giving a detection limit of $100-200 \mu \mathrm{g} / \mathrm{kg}$ of silage (based on the recovery level of mycophenolic acid).

Visually moldy silage samples contained up to $20 \mathrm{mg} / \mathrm{kg}$ (74 

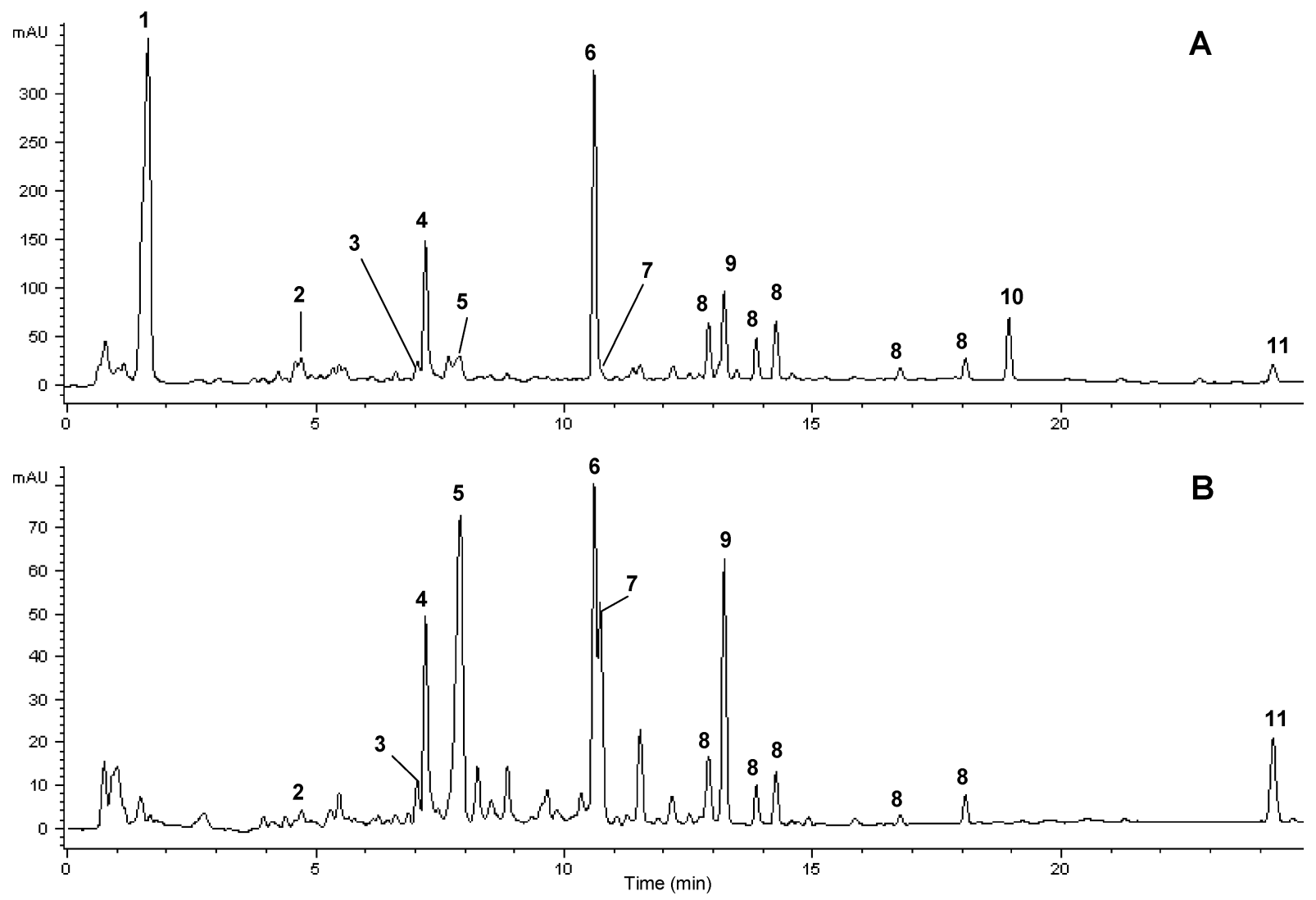

Figure 2. HPLC-UV chromatograms at (A) $210 \mathrm{~nm}$ and (B) $254 \mathrm{~nm}$ of extract of $P$. roqueforti KK09A grown on yeast extract sucrose agar and Czapek yeast autolysate agar at $25^{\circ} \mathrm{C}$ for 7 days. The selected metabolites annotated are (1) an unidentified metabolite, (2) roquefortine $\mathrm{A}$, (3) citreoisocoumarin, (4) roquefortine C, (5) eremofortin C, (6) mycophenolic acid, (7) PR toxin, (8) mycophenolic analogue, (9) andrastin A, (10) linoleic acid, and (11) ergosterol.



Figure 3. HPLC-UV chromatograms at $210 \mathrm{~nm}$ of extract of $P$. paneum KE28B grown on yeast extract sucrose agar, Czapek yeast autolysate agar, and potato dextrose agar (Oxoid) at $25^{\circ} \mathrm{C}$ for 7 days. The selected metabolites annotated are (1) an unidentified metabolite, (2) patulin, (3) triacetic acid lactone, (4) 2,5-dihydroxybenzoic acid, (5) 3-hydroxybenzoic acid, (6) citreoisocoumarin, (7) marcfortine A, (8) roquefortine C, (9) 6-methylsalicylic acid, (10) andrastin B, (11) andrastin A, (12) an unidentified metabolite (MW 304), (13) andrastin D, (14) andrastin C, (15) linoleic acid, and (16) ergosterol.

$\mathrm{mg} / \mathrm{kg}$ of DM) each of roquefortine $\mathrm{C}$, mycophenolic acid, and andrastin A along with minor quantities $(0.1-5 \mathrm{mg} / \mathrm{kg})$ of the roquefortines $\mathrm{A}, \mathrm{B}$, and $\mathrm{D}$, festuclavine, marcfortine $\mathrm{A}$, and agroclavine (Table 4). Visually nonmoldy silage samples contained low amounts $(<0.1-5 \mathrm{mg} / \mathrm{kg})$ of mycophenolic acid and andrastin A, confirming the observations of both Auerbach et al. and O'Brien et al. $(10,46)$ that $P$. roqueforti may be found in apparently clean silages. Roquefortine $\mathrm{C}$ levels in both visually nonmoldy and moldy wilted grass silage in northern Germany ranged from 0.1 to $0.3 \mathrm{mg} / \mathrm{kg}$ of $\mathrm{DM}$ and from 0.2 to
$1.5 \mathrm{mg} / \mathrm{kg}$ of DM, respectively (10), and this compares to none detected in visually nonmoldy samples and between 11.1 and $73.5 \mathrm{mg} / \mathrm{kg}$ of DM $(5-20 \mathrm{mg} / \mathrm{kg})$ in moldy silage samples in this study (Table 4). However, in the German study, moldy whole-crop maize silage samples contained up to $36 \mathrm{mg} / \mathrm{kg}$ of DM of roquefortine C (10). Armbruster (47) detected roquefortine $\mathrm{C}$ in 3 of 24 grass silage samples in concentrations ranging from $<0.1$ to $0.58 \mathrm{mg} / \mathrm{kg}$, but, similar to the findings of Auerbach et al. (10), higher concentrations of up to $28 \mathrm{mg} /$ $\mathrm{kg}$ were found in whole-crop maize silage. Mycophenolic acid 

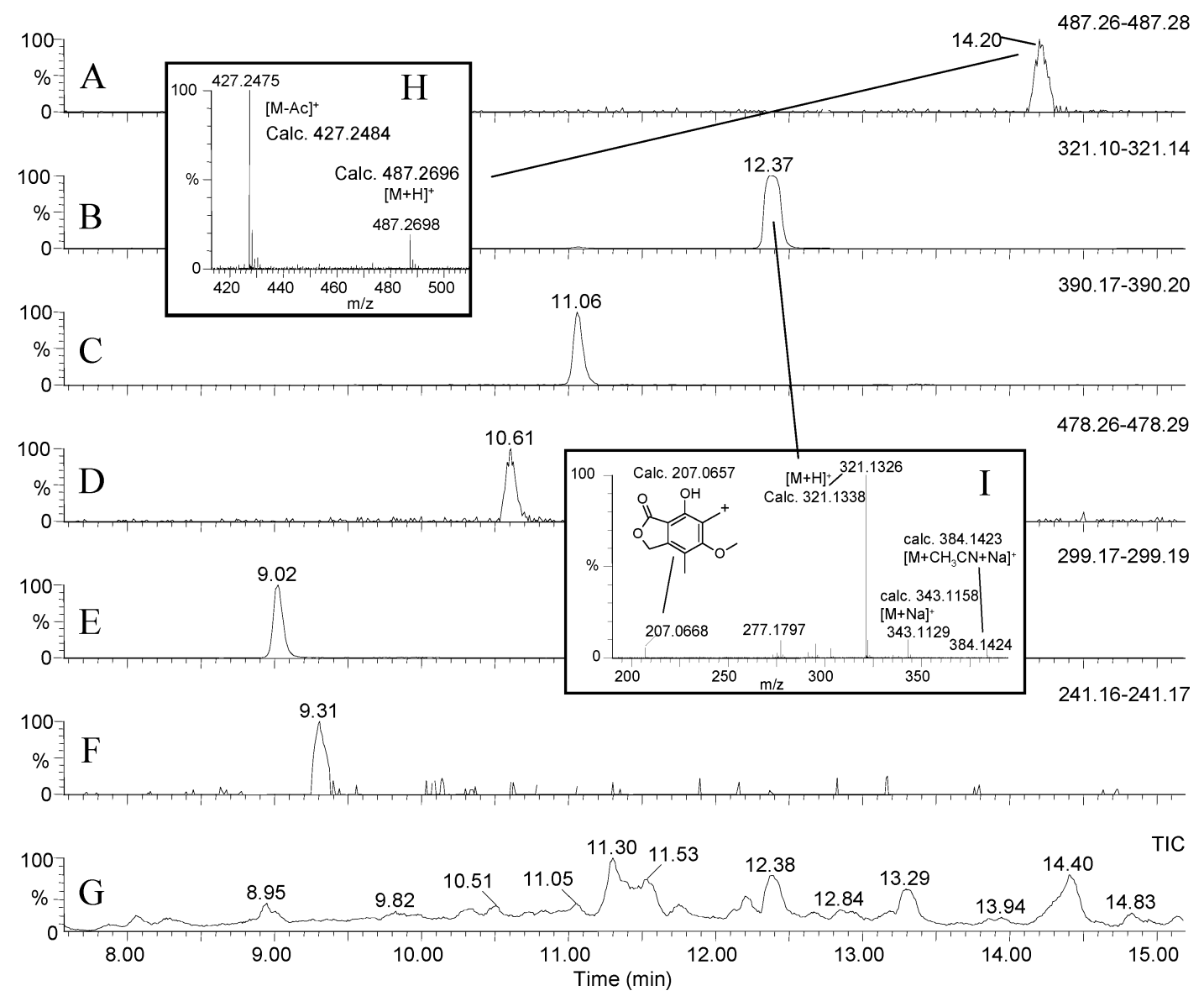

Figure 4. HPLC-MS chromatograms of naturally contaminated moldy silage, showing the extracted ion chromatograms of the $[\mathrm{M}+\mathrm{H}]^{+}$ion of $(\mathbf{A})$ andrastin $A,(\mathbf{B})$ mycophenolic acid (same as PR toxin), (C) roquefortine $\mathbf{C},(\mathbf{D})$ marcfortine $A,(\mathbf{E})$ roquefortine $A$, and $(\mathbf{F})$ festucalvine. (G) Total ion chromatogram (TIC) and the $\mathrm{ESI}^{+}$spectra of $(\mathrm{H})$ andrastin $\mathrm{A}$ and $(\mathbf{I})$ mycophenolic acid.

Table 4. Secondary Metabolites Detected in Fresh Samples of Grass Silage from Bales in Ireland

\begin{tabular}{cccccccccccc} 
sample & $\mathrm{FC}^{d}$ & $\mathrm{AC}$ & $\mathrm{RA}$ & $\mathrm{RB}$ & $\mathrm{OHRC}$ & $\mathrm{RC}$ & $\mathrm{RD}$ & $\mathrm{MA}$ & $\mathrm{ClC}$ & $\mathrm{MPA}$ & $\mathrm{AA}$ \\
\hline $1^{a}$ & ++ & ++ & +++ & ++ & ++ & ++++ & ++ & ++ & tr & ++++ & ++++ \\
$2^{a}$ & ++ & ++ & +++ & ++ & $\mathrm{ND}$ & ++++ & ++ & ++ & tr & ++++ & ++++ \\
$3^{b}$ & $\mathrm{ND}$ & $\mathrm{ND}$ & $\mathrm{ND}$ & $\mathrm{ND}$ & $\mathrm{ND}$ & $\mathrm{ND}$ & $\mathrm{ND}$ & $\mathrm{ND}$ & $\mathrm{ND}$ & $\mathrm{tr}$ & ++ \\
$4^{b}$ & $\mathrm{ND}$ & $\mathrm{ND}$ & $\mathrm{ND}$ & $\mathrm{ND}$ & $\mathrm{ND}$ & $\mathrm{ND}$ & $\mathrm{ND}$ & + & $\mathrm{ND}$ & +++ & ++ \\
$5^{c}$ & $\mathrm{ND}$ & $\mathrm{ND}$ & $\mathrm{ND}$ & $\mathrm{ND}$ & $\mathrm{ND}$ & $\mathrm{ND}$ & $\mathrm{ND}$ & $\mathrm{ND}$ & $\mathrm{ND}$ & tr & ++
\end{tabular}

${ }^{a}$ Visually moldy silage (fungus identified as $P$. roqueforti). ${ }^{b}$ Visually nonmoldy silage adjacent to mold colonies on the same bale. ${ }^{c}$ Visually nonmoldy silage from a bale free of all visible mold growth on its surface. Bale 1, samples 1 and 3 [dry matter $(\mathrm{DM})=27.2 \%$ ]; bale 2, samples 2 and $4(\mathrm{DM}=44.8 \%)$; bale 3 , sample $5(\mathrm{DM}=51.9 \%) ;++++, 5-20 \mathrm{mg} / \mathrm{kg}$ range; +++, $1-5 \mathrm{mg} / \mathrm{kg}$ range; ++, $0.1-1 \mathrm{mg} / \mathrm{kg}$ range;,$+<0.1 \mathrm{mg} / \mathrm{kg}$. Metabolites were detected by LC-ESI+-MS,

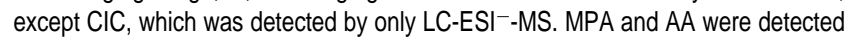

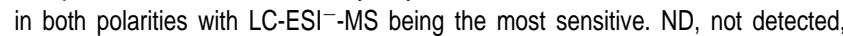
which equals $<40-200 \mu \mathrm{g} / \mathrm{kg}$ of all metabolites except $\mathrm{ClC}$; tr, trace; peak detected $(\mathrm{s} / \mathrm{n}<10) .{ }^{d}$ Abbreviations: FC, festuclavine; AC, agroclavine; RA, roquefortine $A$, $R B$, roquefortine $B ; R C$, roquefortine $C$; OHRC, 16-hydroxyroquefortine $C ; R D$, roquefortine $D ; M A$, marcfortine $A ; C I C$, citreoisocuomarin; MPA, mycophenolic acid; $A A$, andrastin $A$.

levels in grass silage in Bavaria, Germany, ranged from 0.02 to $35 \mathrm{mg} / \mathrm{kg}$ (35); it was detected in $30 \%$ of samples, but as this concentration was not corrected for DM content, it is difficult to make comparison to values recorded in this study. Müller and Amend (36) studied the accumulation of mycotoxins in maize silage inoculated with different strains of $P$. roquefort $i$ (sensu lato) over 160 days of aerobic storage and detected levels of mycophenolic acid, patulin, penicillic acid, and PR toxin to levels of $4,15,3$, and $2 \mathrm{mg} / \mathrm{kg}$ of silage, respectively.

Notwithstanding that the Penicillium-like colonies growing on bales were identified as $P$. roqueforti, the presence of marcfortine A with mycophenolic acid in three of the silage samples suggests that $P$. paneum and $P$. roqueforti were present together because $P$. paneum is the only known producer of marcfortine. Nielsen et al. (11) have suggested that the occurrence of $P$. paneum in silage is probably underestimated due to its misidentification as $P$. roqueforti and also possibly due to its comparatively lower levels of sporulation. An alternative explanation that another fungus in silage is also capable of producing marcfortines seems to be unlikely.

The following metabolites were not detected in any of the silage samples: verruculogen, fumitremorgin B, bis(dethio)bis(methylthio)gliotoxin, or gliotoxin (Aspergillus fumigatus metabolites); citrinin (Monascus metabolite); patulin or marcfortine B ( $P$. paneum metabolites); penicillic acid or penitrem A ( $P$. carneum metabolites). The presence of patulin in feed for livestock would be a concern because it can alter metabolism of nutrients by ruminal microbes (48).

This is the first report of the toxigenic potential of $P$. roqueforti and $P$. paneum growing on grass silage in Ireland. In a Canadian study (15) of mold spoilage of animal feeds, $P$. paneum was associated with ill-thrift of dairy cows, whereas $P$. roqueforti was linked to toxicoses in the animals. Owing to the large number of secondary metabolites produced by these two species in this and other studies, both in culture and in silage, there is a need to carry out multimycotoxin analysis on this feedstuff on a larger scale. A combination of mycotoxins 
and compounds not themselves being toxic rather than any one mycotoxin may be a more likely cause of livestock health problems, and previous studies have not adequately investigated synergistic effects.

In conclusion, this study established the secondary metabolites produced in vitro by $P$. roqueforti and $P$. paneum isolated from baled grass silage in Ireland. Two factors that may affect patulin production by $P$. paneum, that is, trace metal supplements and duration of isolate storage prior to secondary metabolite screening, require further research. Secondary metabolites produced by $P$. roqueforti and also presumably $P$. paneum were detected in visually moldy silage contaminated with $P$. roqueforti and in silage samples that did not appear to be moldy.

\section{ACKNOWLEDGMENT}

We thank Kir Lyhne for technical assistance. We are grateful to farmers for permitting sampling on their farms.

\section{LITERATURE CITED}

(1) O'Kiely, P.; Forristal, D.; Lenehan, J. J.; Fuller, H.; Brady, K.; Barlow, M. Characteristics of baled silage on Irish farms. Farm Food 1998, 8, 29-32.

(2) O'Brien, M.; O'Kiely, P.; Forristal, P. D.; Fuller, H. T. Fungi isolated from contaminated baled grass silage on farms in the Irish Midlands. FEMS Microbiol. Lett. 2005, 247, 131-135.

(3) O'Brien, M.; O'Kiely, P.; Forristal, P. D.; Fuller, H. The extent and identity of visible fungi on baled grass silage at feed-out on farms in the Midlands. In Proceedings of the Agricultural Research Forum; Teagasc: Tullamore, Co. Offaly, Ireland, 2005; $\mathrm{p} 74$.

(4) O’Brien, M.; O'Kiely, P.; Forristal, P. D.; Fuller, H. National survey to establish the extent of visible mould on baled grass silage in Ireland and the identity of the predominant fungal species. In Silage Production and Utilisation. Proceedings of the 14th International Silage Conference; Park, G., Stronge, M. D., Eds.; Wageningen Academic: Wageningen, The Netherlands, 2005; p 252

(5) DiCostanzo, A.; Johnston, L.; Felice, L.; Murphy, M. Effects of molds on nutrient content of feeds reviewed. Feedstuffs 1995, 67, 17.

(6) Lacey, J. Potential hazards to animals and man from microorganisms in fodders and grain. Trans. Br. Mycol. Soc. 1975, 65, 171184.

(7) Fink-Gremmels, J. Mycotoxins in forages. In The Mycotoxin Blue Book; Diaz, D., Ed.; Nottingham University Press: Nottingham, U.K., 2005; pp 249-268.

(8) Pelhate, J. Maize silage: Incidence of moulds during conservation. Folia Vet. Lat. 1977, 7, 1-16.

(9) Skaar, I. Mycological survey and characterisation of the mycobiota of big bale grass silage in Norway. Ph.D. thesis, Norwegian College of Veterinary Medicine, Norway, 1996; 101 pp.

(10) Auerbach, H.; Oldenburg, E.; Weissbach, F. Incidence of Penicillium roqueforti and roquefortine $\mathrm{C}$ in silages. J. Sci. Food Agric. 1998, 76, 565-572.

(11) Nielsen, K. F.; Sumarah, M. W.; Frisvad, J. C.; Miller, J. D. Production of metabolites from the Penicillium roqueforti complex. J. Agric. Food Chem. 2006, 54, 3756-3763.

(12) Boysen, M.; Skouboe, P.; Frisvad, J.; Rossen, L. Reclassification of the Penicillium roqueforti group into three species on the basis of molecular genetic and biochemical profiles. Microbiology 1996, 142, 541-549.

(13) Samson, R. A.; Seifert, K. A.; Kuijpers, A. F. A.; Houbraken, J. A. M. P.; Frisvad, J. C. Phylogenetic analysis of Penicillium subgenus Penicillium using partial $\beta$-tubulin sequences. Stud. Mycol. 2004, 49, 175-200.
(14) Boysen, M. E.; Jacobsson, K. G.; Schnürer, J. Molecular identification of species from the Penicillium roqueforti group associated with spoiled animal feed. Appl. Environ. Microbiol. 2000, 66, 1523-1526.

(15) Sumarah, M. W.; Miller, J. D.; Blackwell, B. A. Isolation and metabolite production by Penicillium roqueforti, $P$. paneum and P. crustosum isolated in Canada. Mycopathologia 2005, 159, 571-577.

(16) Häggblom, P. Isolation of roquefortine $\mathrm{C}$ from feed grain. Appl. Environ. Microbiol. 1990, 56, 2924-2926.

(17) Frisvad, J. C.; Samson, R. A. Polyphasic taxonomy of Penicillium subgenus Penicillium. A guide to identification of the food and air-borne terverticillate Penicillia and their mycotoxins. Stud. Mycol. 2004, 49, 1-173.

(18) Samson, R. A.; Hoekstra, E. S.; Frisvad, J. C.; Filtenborg, O. Introduction to Food- and Airborne Fungi; Centraalbureau voor Schimmelcultures: Utrecht, The Netherlands, 2002; 389 pp.

(19) Frisvad, J. C.; Smedsgaard, J.; Larsen, T. O.; Samson, R. A. Mycotoxins, drugs and other extrolites produced by species in Penicillium subgenus Penicillium. Stud. Mycol. 2004, 49, 201241.

(20) Cole, R. J.; Cox, R. H. Handbook of Toxic Fungal Metabolites; Academic Press: New York, 1981; 937 pp.

(21) Moulé, Y.; Jemmali, M.; Darracq, N. Inhibition of protein synthesis by PR toxin, a mycotoxin from Penicillium roqueforti. FEBS Lett. 1978, 88, 341-344.

(22) Moulé, Y.; Jemmali, M.; Rousseau, N. Mechanism of the inhibition of transcription by PR toxin, a mycotoxin from Penicillium roqueforti. Chem. Biol. Interact. 1976, 14, 207216.

(23) Ueno, Y.; Kubota, K.; Ito, T.; Nakamura, Y. Mutagenicity of carcinogenic mycotoxins in Salmonella typhimurium. Cancer Res. 1978, 38, 536-542.

(24) Polonelli, L.; Lauriola, L.; Morace, G. Preliminary studies on the carcinogenic effects of Penicillium roqueforti (PR toxin) on rats. Mycopathologia 1982, 78, 125-127.

(25) Bentley, R. Mycophenolic acid: a one hundred year odyssey from antibiotic to immunosuppressant. Chem. Rev. 2000, 100, 3801-3825.

(26) Tüller, G.; Armbruster, G.; Wiedenmann, S.; Hänichen, T.; Schams, D.; Bauer, J. Occurrence of roquefortine in silagetoxicological relevance to sheep. J. Anim. Physiol. Anim. Nutr. 1998, 80, 246-249.

(27) Kopp-Holtwiesche, B.; Rehm, H. J. Antimicrobial action of roquefortine. J. Environ. Pathol. Toxicol. Oncol. 1990, 10, 4144.

(28) Rand, T. G.; Giles, S.; Flemming, J.; Miller, J. D.; Puniani, E. Inflammatory and cytotoxic responses in mouse lungs exposed to purified toxins from buildings isolated Penicillium brevicompactum Dierckx and $P$. chrysogenum Thom. Toxicol. Sci. 2005, 87, 213-222.

(29) Nielsen, K. F.; Dalsgaard, P. W.; Smedsgaard, J.; Larsen, T. O. Andrastins A-D, Penicillium roqueforti metabolites consistently produced in blue-mold-ripened cheese. J. Agric. Food Chem. 2005, 53, 2908-2913.

(30) Rho, M. C.; Toyoshima, M.; Hayashi, M.; Uchida, R.; Shiomi, K.; Komiyama, K.; Omura, S. Enhancement of drug accumulation by andrastin A produced by Penicillium sp. FO-3929 in vincristine-resistant KB cells. J. Antibiot. 1998, 51, 68-72.

(31) Smith, D. F.; Lynch, G. P. Aspergillus fumigatus in samples of moldy silage. J. Dairy Sci. 1972, 56, 828-829.

(32) Still, P. E.; Wei, R.; Smalley, E. B.; Strong, F. M. A mycotoxin from Penicillium roqueforti isolated from toxic cattle feed. Fed. Proc. 1972, 31, 733.

(33) Vesely, D.; Veselá, D.; Adámková, A. Occurrence of the mold Penicillium roqueforti producing PR-toxin in maize silage. Vet. Med. 1981, 26, 109-115.

(34) Garon, D.; Richard, E.; Sage, L.; Bouchart, V.; Pottier, D.; Lebailly, P. Mycoflora and multimycotoxin detection in corn silages: experimental studies. J. Agric. Food Chem. 2006, 54, 3479-3484. 
(35) Schneweis, I.; Meyer, K.; Hörmansdorfer, S.; Bauer, J. Mycophenolic acid in silage. Appl. Environ. Microbiol. 2000, 66, 3639-3641.

(36) Müller, H. M.; Amend, R. Formation and disappearance of mycophenolic acid, patulin, penicillic acid and PR toxin in maize silage inoculated with Penicillium roqueforti. Arch. Anim. Nutr. 1997, 50, 213-225.

(37) Pitt, J. I. A Laboratory Guide to Common Penicillium Species; Food Science Australia: North Ryde, NSW, Australia, 2000; 197 pp.

(38) Dombrink-Kurtzman, M. A.; Blackburn, J. A. Evaluation of several culture media for production of patulin by Penicillium species. Int. J. Food Microbiol. 2005, 98, 241-248.

(39) Smedsgaard, J. Micro-scale extraction procedure for standardized screening of fungal metabolite production in cultures. J. Chromatogr. A 1997, 760, 264-270.

(40) Nielsen, K. F.; Gräefenhan, T.; Zafari, D.; Thrane, U. Trichothecene production by Trichoderma brevicompactum. J. Agric. Food Chem. 2005, 53, 8190-8196.

(41) Nielsen, K. F.; Smedsgaard, J. Fungal metabolite screening: database of 474 mycotoxins and fungal metabolites for dereplication by standardised liquid chromatography-UV-mass spectrometry methodology. J. Chromatogr. A 2003, 1002, 111136.

(42) Moreau, S.; Lablache-Combier, A.; Biguet, J.; Foulon, C.; Delfosse, C. Botryodiploidin, a mycotoxin synthesized by a strain of $P$. roqueforti. J. Org. Chem. 1982, 47, 2358-2359.

(43) Frisvad, J. C.; Filtenborg, O. Terverticillate penicillia: chemotaxonomy and mycotoxin production. Mycologia 1989, 81, 837861.
(44) Scott, R. E.; Jones, A.; Lam, K. S.; Gaucher, G. M. Manganese and antibiotic biosynthesis. 1. A specific manganese requirement of patulin production in Penicillium urticae. Can. J. Microbiol. 1986, 32, 259-267.

(45) Santos, I. M.; Abrunhosa, L.; Venâncio, A.; Lima, N. The effect of culture preservation techniques on patulin and citrinin production by Penicillium expansum Link. Lett. Appl. Microbiol. 2002, 35, 272-275.

(46) O’Brien, M.; O’Kiely, P.; Forristal, P. D.; Fuller, H. T. Quantification and identification of fungal propagules in wellmanaged baled grass silage and in normal on-farm produced bales. Anim. Feed Sci. Technol. 2007, 132, in press.

(47) Armbruster, G. Feed hygienical investigations of silages: detection and occurrence of the mycotoxin roquefortine. Ph.D. thesis, München, 1994; 103 pp.

(48) Tapia, M. O.; Stern, M. D.; Koski, R. L.; Bach, A.; Murphy, M. J. Effects of patulin on rumen microbial fermentation in continuous culture fermenters. Anim. Feed Sci. Technol. 2002, 97, 239-246.

Received for review July 25, 2006. Revised manuscript received September 25, 2006. Accepted September 29, 2006. A Teagasc Walsh Fellowship Research Scholarship awarded to M.O'B. supported this study. This research was also funded by the EU 5th Framework Program; a visit to BioCentrum-DTU, Denmark, by M.O'B. was facilitated on an "Access to Research Infrastucture" award. We thank the Danish Technical Research Council and the Centre for Advanced Food Studies (LMC) for supporting this study.

JF0621018 